\title{
Inhibition and synchronisation of tremor induced by a muscle twitch
}

\author{
N BATHIEN, P RONDOT, AND S TOMA \\ From the Department of Neurology, Fac Med Cochin-Port Royal and the Laboratory of Physiology, \\ Fac Med Saint-Antoine, Paris
}

SUMMARY The effects of a muscle twitch on the tremor of the extensor indicis muscle and of the tibial anterior muscle have been recorded in 14 patients with essential tremor and in 10 patiente with Parkinson's disease. The muscle twitch evoked by the electrical stimulation of the motor nervr inhibits the tremor and synchronises it. The mean duration of the inhibition is $92 \cdot 1 \pm 6 \cdot 8 \mathrm{~ms}$ for essential tremor and $183.0 \pm 16.8 \mathrm{~ms}$ for Parkinsonian tremor. This inhibitory phase lasts longee when the muscle twitch is induced during the second half of the Parkinsonian tremor cycle. Thr effects of voluntary contraction and of unloading suggest that inhibition and resetting of the tremor can be attributed to the autogenic mechanism induced by Ib fibres discharges. The presence of a rhythmic inhibition in the cycle of Parkinsonian tremor accounts for the longer duration of the inhibitory phase. In practice, these techniques aid the diagnosis of tremor in these two conditions, for example they assist the identification of low frequency essential tremor and of postural tremor in Parkinson's disease.

A muscle twitch elicited by electrical stimulation of a nerve provokes a halt in the rhythmic activity of Parkinsonian tremor lasting 200$250 \mathrm{~ms}$. The tremor EMG bursts which reappear after this inactive phase change in frequency for a short period.12 The duration of this inactive phase is much longer than the classical silent period $^{3-5}$ induced by a twitch upon a muscle in voluntary contraction. Thus, Parkinsonian tremor can be suppressed and reset by peripheral stimulation. Recently, Teravainen et $a l^{6}$ have also shown that short external perturbations in limb position change the phase of Parkinsonian resting tremor.

The present study investigates this phenom. enon both in essential tremor and Parkinsonian tremor, to see if it is specific to the latter, and investigates the pathophysiological mechanisms involved.

\section{Method}

1 Patients Ten patients with Parkinsonian tremor and 14 patients with essential tremor

Address for reprint requests: Dr N Bathien, Laboratory of Physiology, Fac Med Saint-Antoine, 27, rue Chaligny, 75571 Paris Cedex 12, France.

Accepted 22 January 1980 were studied. Relevant clinical features are summarised in tables 1 and 2. Tremor was the main symptom of the disease in five cases in the Parkinsonian group. The ages of the patients ranged from 46 to 69 years. In the group of patients with essential tremor, a family history was found in five cases. The duration of the tremor ranged from three months to 17 years and the ages of the subjects from 27 to 79 years.

Table 1 Clinical data and related EMG findings in patients with essential tremor

\begin{tabular}{llllll}
\hline Patient & Sex & $\begin{array}{l}\text { Age } \\
(y r)\end{array}$ & $\begin{array}{l}\text { Ilness } \\
\text { duration } \\
(y r)\end{array}$ & $\begin{array}{l}\text { Tremor } \\
\text { frequency } \\
H z\end{array}$ & $\begin{array}{l}\text { Duration } \\
\text { of } \\
\text { IPIMT }\end{array}$ \\
\hline 1 & M & 44 & 17 & $6-7$ & 80 \\
2 & F & 26 & 14 & $10-12$ & 80 \\
3 & F & 70 & 15 & $10-12$ & 80 \\
4 & M & 49 & 31 & $5-6$ & 100 \\
5 & F & 57 & $0 \cdot 41$ & $10-12$ & 80 \\
6 & M & 74 & 5 & 10 & 100 \\
7 & M & 44 & 10 & $10-12$ & 90 \\
8 & M & 30 & 2 & 10 & 120 \\
9 & M & 71 & $0 \cdot 50$ & $8-12$ & 80 \\
10 & F & 38 & $0 \cdot 25$ & 9 & 80 \\
11 & F & 71 & 5 & $5-6$ & 100 \\
12 & M & 53 & 3 & 8 & 100 \\
13 & M & 51 & 2 & 10 & 100 \\
14 & M & 79 & 3 & $5-6$ & 100 \\
Mean & & $54 \cdot 07$ & $7 \cdot 72$ & $9 \cdot 0$ & $92 \cdot 1$ \\
SD & & & & $2 \cdot 3$ & $12 \cdot 5$ \\
SE & & & & $0 \cdot 6$ & $3 \cdot 4$ \\
\hline
\end{tabular}


Table 2 Clinical data and related EMG findings in patients with Parkinsonian tremor

\begin{tabular}{|c|c|c|c|c|c|c|c|}
\hline Patient & Sex & $\begin{array}{l}\text { Age } \\
(y r)\end{array}$ & $\begin{array}{l}\text { Illness } \\
\text { duration } \\
(y r)\end{array}$ & Exam & Medication & $\begin{array}{l}\text { Tremor } \\
\text { frequency } \\
\mathrm{Hz}\end{array}$ & $\begin{array}{l}\text { Duration } \\
\text { of } \\
\text { IPIMT }\end{array}$ \\
\hline 1 & $\mathbf{F}$ & 68 & 0.41 & $\mathbf{R}, \mathbf{A K}$ & $\begin{array}{l}\text { Amantadine } \\
\text { Artane }\end{array}$ & $5-6$ & 180 \\
\hline 2 & $\mathbf{F}$ & 69 & 4 & $\mathbf{R}, \mathbf{A K}$ & $\begin{array}{l}\text { L-Dopa } \\
\text { Artane }\end{array}$ & $4-5$ & 160 \\
\hline 3 & $\mathbf{M}$ & 46 & 5 & 0 & $\begin{array}{l}\text { L-Dopa } \\
\text { Amantadine }\end{array}$ & $4-5$ & 170 \\
\hline 4 & $\mathbf{M}$ & 54 & 4 & 0 & $\begin{array}{l}\text { L-Dopa } \\
\text { DCI }\end{array}$ & $4-5$ & 200 \\
\hline 5 & $\mathbf{F}$ & 66 & 10 & 0 & $\begin{array}{l}\text { L-Dopa-DCI } \\
\text { Artane }\end{array}$ & $5-6$ & 150 \\
\hline 6 & $\mathbf{M}$ & 52 & 10 & $\mathrm{R}, \mathrm{AK}$ & $\begin{array}{l}\text { L-Dopa, DCI } \\
\text { Amantadine }\end{array}$ & $5-6$ & 170 \\
\hline 7 & $\mathbf{M}$ & 59 & 5 & 0 & $\begin{array}{l}\text { L-Dopa } \\
\text { B-blocker }\end{array}$ & $6-7$ & 160 \\
\hline 8 & $\mathbf{M}$ & 69 & 22 & 0 & L-Dopa & 5 & 220 \\
\hline 9 & $\mathbf{F}$ & 59 & 8 & AK & L-Dopa & $6-7$ & 200 \\
\hline 10 & $\mathbf{M}$ & 52 & 7 & R, AK & $\begin{array}{l}\text { L-Dopa } \\
\text { Amantadine }\end{array}$ & $5-6$ & 220 \\
\hline $\begin{array}{l}\text { Mean } \\
\text { SD } \\
\text { SF }\end{array}$ & & $59 \cdot 4$ & $7 \cdot 5$ & & & $\begin{array}{l}5.4 \\
0.7 \\
0.2\end{array}$ & $\begin{array}{r}183 \cdot 0 \\
25 \cdot 4 \\
8 \cdot 4\end{array}$ \\
\hline
\end{tabular}

$\mathrm{R}$ : rigidity. AK: akinesia. IPIMT: inactive phase induced by a muscle twitch.

The patients gave informed consent to all the investigations and procedures carried out.

2 Electrophysiological methods The analysis of the muscle twitch effect on tremor was mainly performed on the extensor indicis muscle (EI). In some cases, Parkinsonian tremor was studied both in extensor indicis and in tibialis anterior.

The subject was seated in a chair, the upperlimb semi-flexed, the forearm relaxed on the table for study of extensor indicis tremor. The leg was extended, the knee slightly flexed for study of tibialis anterior tremor.

A muscle twitch was induced by electrical stimulation. Extensor indicis twitch was evoked by stimulation of the radial nerve at the arm and tibialis anterior twitch was evoked by stimulation of the peroneal nerve at the knee. The stimulus was a square-wave impulse of $1.0 \mathrm{~ms}$ duration at a frequency of $1.0 \mathrm{hz}$. Stimulation was triggered at varying times in the tremor cycle.

The classical silent period was studied by examining the unloading reaction of the extensor indicis muscle. The patient was sitting comfortably in a chair, with the hand, the wrist and the elbow fixed on a support. The index finger was splinted so that only the metacarpophalangeal joint could move, to which a weight was attached by a cord running over a pulley. The patient was asked to keep the finger horizontal. The unloading reaction was obtained by cutting the cord.

The electromyographic responses (EMG) were recorded by surface electrodes. Tremor activity was obtained by a single plane accelerometer (Grass SPA 1). During the experiments, EMG signals and tracings of tremor were continuously displayed by an oscilloscope and a loud-speaker. Selected sequences were stored on an analog tape recorded (Philips Minilog 4) for subsequent photographic and computer analysis.

\section{Results}

1 Muscle twitch effects on Parkinsonian tremor An example of the effects of a muscle twitch taken from a single subject on Parkinsonian tremor is illustrated in fig 1 . The histogram of intervals of 100 cycles of this tremor presents a mean interval of $204 \cdot 2 \pm 30.0 \mathrm{~ms}$, corresponding to a frecuency of $5.4 \pm 0.7 \mathrm{~Hz}$. A supramaximal stimulation of the radial nerve which induced a muscle twitch of the extensor indicis, had a double effect on the Parkinsonian tremor rhythm recorded in that same muscle:

a The radial nerve stimulation synchronised the bursting pattern of the extensor indicis. The EMG activity was increased in the first burst as well as in the following one or two bursts. An cscillaticn of the period of the rhythm was cbserved along with the oscillation of the amplitude of the tremor. The mean duration of the oscillation of the period of the rhythm was 600 to $800 \mathrm{~ms}$.

$b$ The radial nerve stimulation induced an EMG silence which lasted from 160 to $260 \mathrm{~ms}$ (table 2). The mean duration recorded from 10 Parkinsonian patients was $183.0 \pm 16.8 \mathrm{~ms}$ (mean 


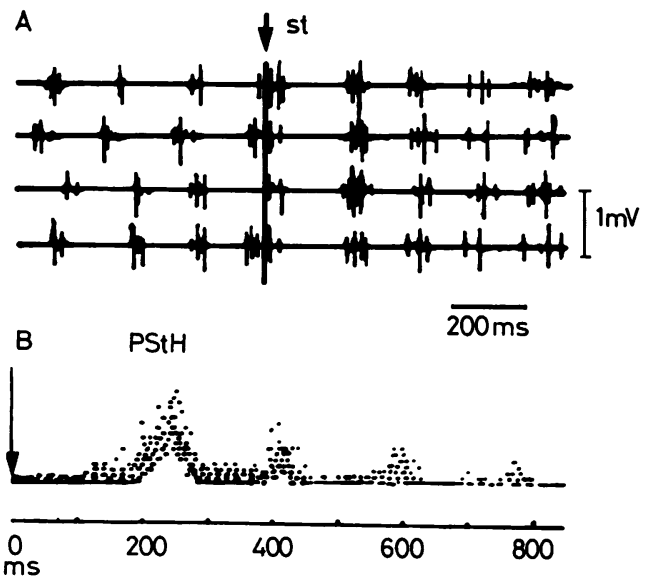

Fig 1 Effects of muscle twitch induced by the stimulation of radial nerve (St) on Parkinsonian tremor recorded in extensor indicis. A-typical EMG recordings of Parkinsonian tremor and changes evoked by a muscle twitch. Note the resetting of tremor activity and the inactive (inhibitory) phase duration. B-post-stimulus histogram (PStH) of tremor activity. Calibrations: $1 \mathrm{mV}$ and $200 \mathrm{~ms}$.

\pm 2 standard errors). When the suppression was not complete, that is radial nerve stimulation was not supra-maximal and induced only a weak extensor indicis muscle twitch, a burst of tremor of small amplitude could be recorded during the inactive period.

The same pattern of results was recorded in the fibralis anterior muscle on stimulating the rercneal nerve in five of the same Parkinsonian patients.

2 Muscle twitch effects on essential tremor

Essential tremor is commonly observed in the upper limb. Muscle twitch effects were studied in extensor indicis on stimulating the radial nerve. The frequency of tremor recorded in extensor indicis muscle ranged from 5 to $6 \mathrm{~Hz}$ in four cases and from eight to 12 cases. The same pattern of results was obtained in the 14 patients (table 1).

The ability of muscle twitch to synchronise bursts in extensor indicis and to suppress the EMG activity is shown in fig 2 . The superimposed vertical lines of stimulation artefact between the records show that tremor, which initially was bursting out of phase was now synchronised.

The post-stimulating histogram shows that, as in Parkinsonian tremor synchronisation

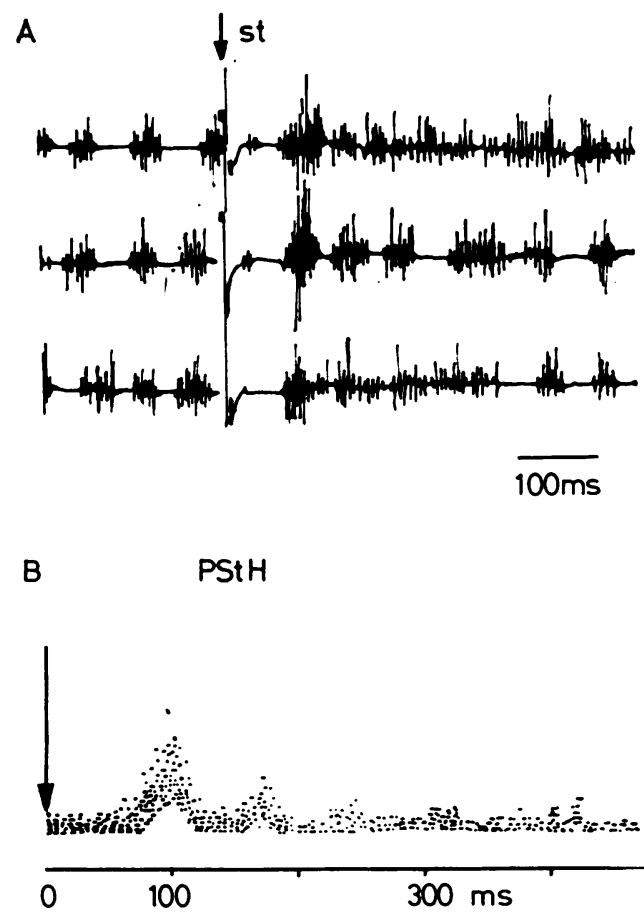

Fig 2 Effects of muscle twitch on essential tremor. EMG recordings $(A)$ and post-stimulus histogram (PStH) as in fig 1 . Note the resetting of tremor activity and the shorter inactive (inhibitory) phase duration.

Calibrations: $0.5 \mathrm{mV}$ and $100 \mathrm{~ms}$.

lasts about 3 or 4 tremor cycles; mean duration of the inactivation induced by muscle twitch was $92 \cdot 1 \pm 6 \cdot 8 \mathrm{~ms}$ in the 14 patients.

3 Modulation of the effects induced by $a$ muscle twitch

(a) Inactive phase and tremor cycle The duration of inhibition induced by the muscle twitch at four different points of the tremor cycle is shown in fig 3. In the Parkinsonian patients, the tremor cycle lasted $200 \mathrm{~ms}$ and burst duration $80 \mathrm{~ms}$. When the muscle twitch was presented during the burst, the occurrence of the next burst was slightly delayed. When it was presented later in the tremor cycle $(150 \mathrm{~ms}$ and $180 \mathrm{~ms}$ after the onset of the burst), the next burst was significantly more delayed. The longest inactive phase occurred with the muscle twitch near the end of the tremor cycle.

On the other hand, the tremor cycle was more variable in essential tremor and its duration was $91 \cdot 0 \pm 9.0 \mathrm{~ms}$. The inactive phase evoked 

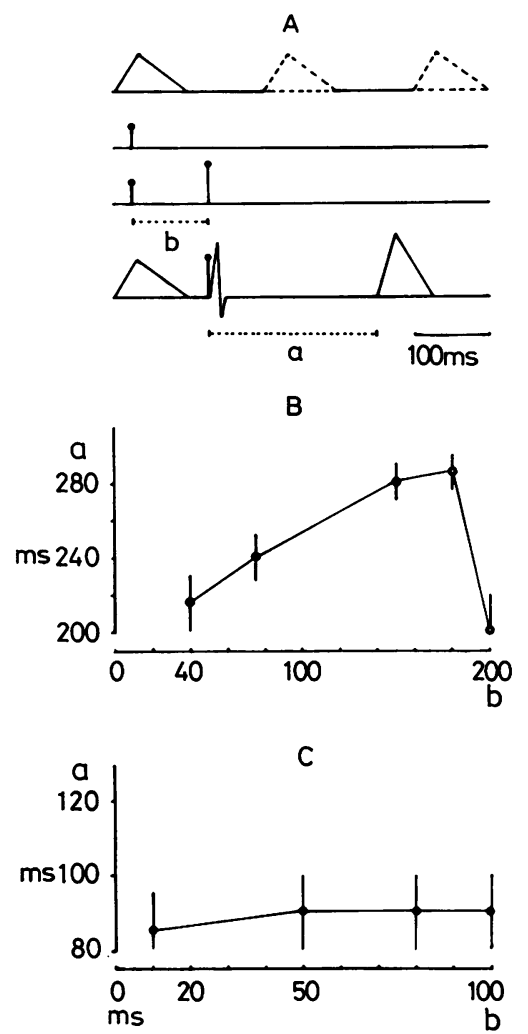

Fig 3 Changes in the inactive phase duration evoked by a muscle twitch as a function of its place in the tremor cycle. A. Schematic illustration of the method used to calculate the coordinates of the curves $\boldsymbol{B}$ for Parkinsonian tremor and $C$ for essential tremor. Ordinates (a): inhibition-duration measured from the stimulation to the onset of the first tremor burst. Mean $\pm 2 \operatorname{SEM}(N=10)$ not represented. Abscissa (b): Latency of the stimulation triggered from the pre-stimulus burst. Note the increase of the inhibition duration in Parkinsonian tremor only when the muscle-twitch was in the later phases of tremor cycle.

by the muscle twitch did not vary as a function of its timing in the tremor cycle (fig $3 \mathrm{C}$ ).

(b) Effect of isometric voluntary contraction which produces a state of tonic central facilitation of motoneurones. The data recorded from a Parkinsonian patient are illustrated in fig 4 . The mean frequency did not change. The inactive phase induced by a muscle twitch, however, is clearly shorter. Its mean duration was $210 \pm 10 \mathrm{~ms}$ before and $110 \pm 30 \mathrm{~ms}$ during isometric con-
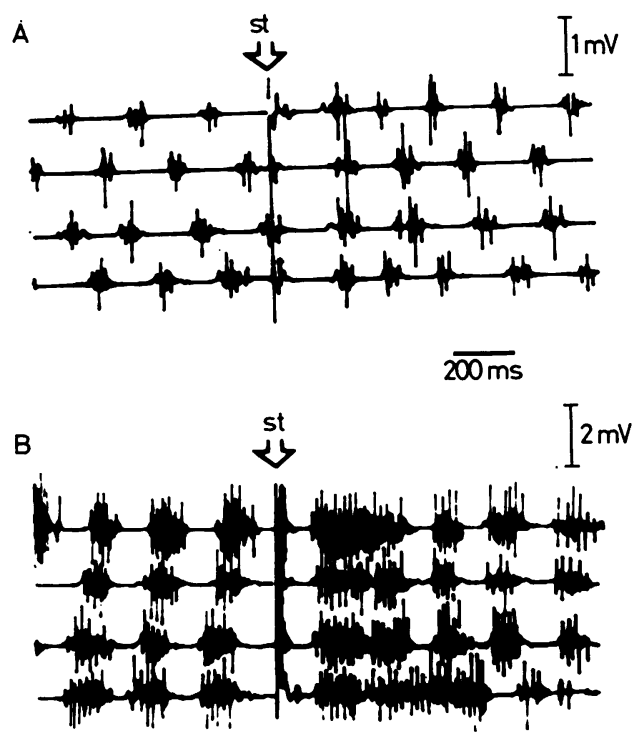

Fig 4 Effects of a muscle twitch on Parkinsonian tremor during tonic voluntary contraction. Note the shorter inactive phase duration during tonic voluntary contraction.

traction. In essential tremor, the inactive phase in the same conditions lasted as long as the classical silent period, ie $90 \pm 20 \mathrm{~ms}$.

(c) Unloading test Data shown in fig 5 refer to the effects of a spindle pause on Parkinsonian tremor and essential tremor. Parkinsonian tremor did not change in frequency when the muscle in tonic contraction was unloaded suddenly. In essential tremor, unloading provoked the usual silent period of $80-100 \mathrm{~ms}$ duration (fig $5 \mathrm{~B}$ ).

\section{Discussion}

1 Mechanism of inhibiting induced by a muscle twitch

The techniques of unit recording from muscle nerves in man have corroborated the experimental data from animals ${ }^{6}$ concerning the discharges induced by a muscle twitch. A spindle pause occurs during the contraction $^{7-11}$ as does activity of $\mathrm{Ib}$ afferents. ${ }^{812}$ The pause of the Ia discharges accounts for the silent period of the "unloading" during an isometric contraction. ${ }^{31314}$ Several phenomena are involved in the mechanism of the muscle twitch-induced silent period described by Hoffmann, ${ }^{15}$ among them the spindle pause and autogenic inhibition. 


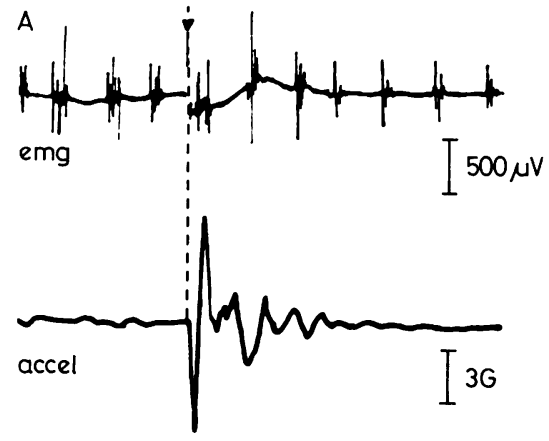

$\overline{200 \mathrm{~ms}}$

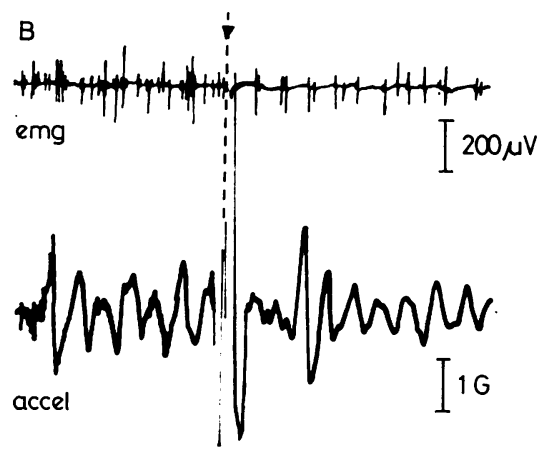

Fig 5 Effects of unloading reflex on Parkinsonian tremor $(A)$ and essential tremor $(B)$. Note that there is no change in frequency in Parkinsonian tremor and a normal silent period in essential tremor.

Bursts of Ia discharges of two kinds appear when recording spindle activity during Parkinsonian tremor ${ }^{16}$ : those synchronous of the tremor bursts and others occurring during the silent period. This Ia activity is different from the continuous Ia discharge observed in an isometric contraction $^{9-11}$ and may minimise the effect of a spindle pause induced by introduction of a muscle twitch in tremor.

The temporary suppression of Parkinsonian tremor noted in this study can be explained by the inhibitory effect of the muscle twitch inducing Ib discharges. The selective excitation of Ia fibres by vibration ${ }^{1}$ and by isometric voluntary contraction doies not suppress but shortens tremor duration. The difference observed between Parkinsonian and essential tremor is another matter, and may be due to the difference in the mechanisms of the two kinds of tremor. ${ }^{2}$

According to oscillator terminology ${ }^{17-19}$ Parkin- sonian tremor is more "isochronous" than essential tremor. Inhibition produced by the muscle twitch may reset a bursting oscillator in two different ways. In essential tremor phase delay is fixed and does not exceed the tremor cycle, so has the same value as a usual silent period. On the other hand, in Parkinsonian tremor the phase delay is a function of the phase of the burst cycle in which the twitch is introduced. In the later phases of the burst cycle, phase delay is relatively long when compared to the burst cycle length. Its duration may be the sum of the inhibition induced by muscle twitch and that inherent to the Parkinsonian tremor mechanism.

2 Segmentary excitability during tremor.

The recording of spindle discharges during Parkinsonian tremor showed that the EMG rhythmic bursts preceded the spindle activity so it can be concluded that the myotatic stretch reflex loop does not take part in the initiation of each rhythmic burst. However, spindle discharge may induce an excitatory effect on the last part of the rhythmic burst and a reciprocal inhibitory effect on antagonist motoneurones. ${ }^{16}$ These data are in favour of a central origin of the tremor rhythm, but do not exclude the role of peripheral afferents in the clinical expression of tremor.

When testing motoneurone excitability by the amplitude of the $\mathrm{H}$ reflex, it appears to decrease during the silent period and to increase just before the next tremor burst. ${ }^{2}$ In the present work the excitability of motoneurones has been tested by inhibitory impulses presented by a muscle twitch. It is known that the normal duration of a silent period evoked by a muscle twitch is $80-120$ ms. $^{5}{ }^{20}$ In essential tremor, the mean duration of inhibition is $92.1 \pm 6.8 \mathrm{~ms}$ (fig 2 and table 1). In Parkinsonian tremor, the duration of the inhibition lasts longer $(183 \cdot 0 \pm 16 \cdot 8)$ and it is even more prolonged if the muscle twitch is triggered during the silent period of the tremor cycle (fig 3). These results suggest that different physiopathological mechanisms are involved in these two kinds of tremor.

\section{References}

1 Renou $\mathbf{G}$, Rondot $\mathbf{P}$, Bathien N. Influence of peripheral stimulation on the silent period between bursts of Parkinsonian tremor. In: Desmedt $\mathrm{JE}$, ed. New developments in EMG and Clinical Neurophysiology, Volume 3. Basle: Karger, 1973: 635-40.

2 Rondot P, Bathien N. Peripheral factors modulating Parkinsonian tremor. In: Birkmayer W, 
Hornykiewicz, eds. Advances in Parkinsonism. Basle: Editiones Roche, 1977: 269-76.

3 Angel RW, Eppler W, Iannone A. Silent period produced by unloading of muscle during voluntary contraction. J Physiol (Lond) 1965; 180: 864-70.

4 Hoffmann P. Demonstration eines Hemmugs reflexes in menschlichen Rückenmark. Z Biol 1919; 70:515-524.

5 Hufschmidt HJ. The demonstration of autogenic inhibition and its significance in human voluntary movement. In: Granit R, ed. Nobel Symposium 1: Muscular afferents and motor control. Stockholm: Almquist and Wiksell, 1966: 269-74.

6 Teräväinen $H$, Evarts E, Calne D. Effects of kinesthetics inputs on Parkinsonian tremor. In: Poirier LJ, Sourkes TL, Bédard PJ, eds. Advances in Neurology. Volume 34. New York: Raven Press, 1979: 161-73.

7 Hagbarth KE, Vallbo AB. Single unit recordings from muscle nerves in human subjects. Acta Physiol (Scand) 1969; 76:321-34.

8 Struppler A. Données actuelles de la mocroneuronographie chez l'homme: intérêt en réflexologie. Rev Electroenceph Clin Neurophysiol 1974; 4:525-538.

9 Vallbo AB. Discharge patterns in human muscle spindle afferents during isometric voluntary contractions. Acta Physiol Scand 1970; 80:552-66.

10 Vallbo AB, Hagbarth KE. Activity from skin mechano-receptors recorded percutaneously in awake human subjects. Exp Neurol 1968; 21: 270-89.

11 Vallbo AB, Hagbarth KE. Micro-electrode recordings from human peripheral nerves. In: Desmedt JE, ed. New developments in EMG and clinical neurophysiology. Volume 2. Basle:
Karger, 1973: 67-84.

12 Szumski AJ, Burg D, Struppler A, Vehlo F. Activity of muscle spindle during muscle twitch and clonus in normal and spastic human subjects. Electroenceph Clin Neurophysiol 1974; 37: 589-97.

13 Angel RW. Spasticity and tremor. In: Desmedt $\mathrm{JE}$, ed. New developments in EMG and clinical neurophysiology. Volume 3. Basle: Karger, 1973: 618-24.

14 Struppler A, Burg D, Erbel F. The unloading reflex under normal and pathological conditions in man. In: Desmedt JE, ed. New developments in EMG and clinical neurophysiology. Volume 3. Basle: Karger, 1973: 603-17.

15 Hoffmann $\mathrm{P}$. Untersuchungen über die Eigenreflexe menschlicher muskeln. Berlin: Springer, 1922.

16 Hagbarth KE, Wallin G, Lofstedt L, Aquilonius SM. Muscle spindle activity in alternating tremor of Parkinsonian and in clonus. $J$ Neurol Neurosurg Psychiatry 1975; 38:636-641.

17 Pavlidis T. Biological oscillators: their mathe. matical analysis. New York: Academic Press, 1973: 207.

18 Pinsker HM. Aplysia bursting neurons an endogenous oscillators: I-phase response curves for pulsed inhibitory synaptic input. J Neurophysiol 1977; 40:527-43.

19 Pinsker HM. Aplysia bursting neurons an endogenous oscillators: II-Synchronisation and entrainment by pulsed inhibitory input. J Neurophysiol 1977; 40:544-57.

20 Shahani BT, Young RR. Studies of the normal human silent period. In: Desmedt JE, ed. New developments in EMG and clinical neurophysiology. Volume 3. Basle: Karger, 1973: 589-602. 